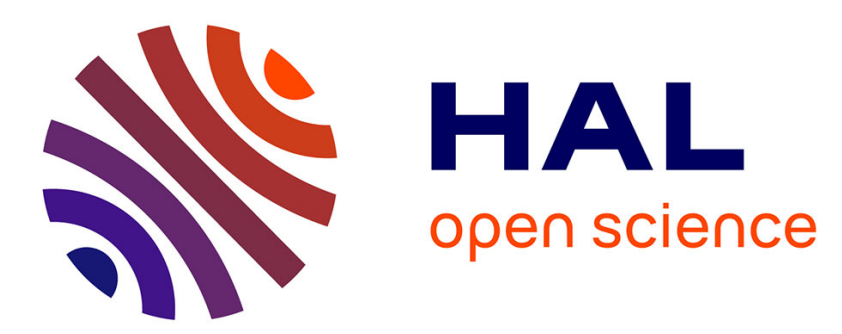

\title{
Production of microporous aluminum oxide electrodes as supports for tethered lipid bilayers of large surface area
}

Ophelie Fliniaux, Celine Elie-Caille, Jacques Pantigny, Christian Bourdillon

\section{To cite this version:}

Ophelie Fliniaux, Celine Elie-Caille, Jacques Pantigny, Christian Bourdillon. Production of microporous aluminum oxide electrodes as supports for tethered lipid bilayers of large surface area. Electrochemistry Communications, 2005, 7, pp.697. hal-00096259

\section{HAL Id: hal-00096259 \\ https://hal.science/hal-00096259}

Submitted on 19 Sep 2006

HAL is a multi-disciplinary open access archive for the deposit and dissemination of scientific research documents, whether they are published or not. The documents may come from teaching and research institutions in France or abroad, or from public or private research centers.
L'archive ouverte pluridisciplinaire HAL, est destinée au dépôt et à la diffusion de documents scientifiques de niveau recherche, publiés ou non, émanant des établissements d'enseignement et de recherche français ou étrangers, des laboratoires publics ou privés. 


\title{
Production of microporous aluminum oxide electrodes as supports for tethered lipid bilayers of large surface area.
}

\author{
Ophélie Fliniaux, Céline Elie-Caille, Jacques Pantigny, Christian Bourdillon * \\ UMR 6022 du CNRS, Université de Technologie de Compiègne, BP 20529, 60205 \\ Compiègne, France \\ ${ }^{*}$ Corresponding author \\ Christian Bourdillon, UMR 6022 du CNRS, Université de Technologie de Compiègne \\ BP 20529, 60205 COMPIEGNE Cedex, FRANCE \\ Tel (33) $344234405 \quad$ Fax (33) 344203910 \\ Email: Christian.Bourdillon@utc.fr
}

\begin{abstract}
A composite electrode made by association of gold and porous aluminum oxide has been used as template for a supported lipid bilayer. An oxide pore size of $170 \mathrm{~nm}$ was chosen so that lipid vesicles or proteoliposomes can enter in the pore and cover the pore wall. Triggered vesicle fusion produced a stable and continuous lipid bilayer supported on the large surface area of the honeycomb structure. Continuity of the supported bilayer was attested by electrochemical measurement of the lateral mobility of ubiquinone, a water-insoluble electroactive marker, dissolved at low concentration in the hydrophobic leaflet of the bilayer.
\end{abstract}

Keywords: Porous aluminum oxide; phospholipid bilayer; two-dimensional electrochemistry; ubiquinone lateral mobility.

\section{Introduction}

The reconstitution of supported bilayers on solid surfaces has been widely investigated in the last decade [i,ii,iii,iv]. The large majority of the published works have dealt with supports of planar geometry which is obligatory for most of the characterization methods. For example: fluorescence microscopy and FRAP (fluorescence recovery after photobleaching) need transparent glass or quartz [v]; SPR (surface plasmon resonance), a flat gold surface [vi]; QCM (quartz crystal microbalance), flat silica or gold surface [vii]; AFM (atomic force microscopy) needs a high quality silicon or mica surface [viii]. 
We have demonstrated that the assembly of a lipid hemilayer or bilayer on a porous template is also quite possible and convenient, especially in the case of an electrochemical characterization [ix,x]. The device, named a "microporous electrode" was made by association of a gold layer as electrode and the honeycomb structure of a porous alumina film used as support for the bilayer. The molecular connection at the bottom of the pores between the gold electrode and the bilayer allow direct electrochemistry on the hydrophobic molecules confined in the bilayer. For example, biological membrane electron carriers like ubiquinone and plastoquinone, connected to the electrode, were able to report the dynamic behavior of the biomimetic structure. The potentiality of this approach was demonstrated by the kinetic coupling between the electrochemical device and a peripheral enzyme, pyruvate oxidase incorporated in the supported hemi-layer [xi].

Our long-term aim is the reconstitution of working electron transport chains and their coupling to the same kind of device. Compared to the relatively simple incorporation of a peripheral enzyme in the artificial structure, the reconstitution of several integral enzymes complexes in a supported membrane is a more complex task. The overall strategy is explained in figure 1.

First, the highly ordered structure of anodic alumina is used as a template for the lipid bilayer (figure 1A). Anodic porous alumina is prepared by oxidation of aluminum in an acidic electrolyte. It presents a surprisingly regular array of hexagonal columnar cells with central, cylindrical, uniformly sized holes ranging from some nanometers to a hundred nanometers. The interest of this nanometer-sized material has been widely recognized because of its potential applications in electronic, optical and micromechanical devices (see, for example, [xii]). The formation of a "microporous electrode" from this structure by vapor deposition of a gold layer in such a way that the electrode closes one side of the honeycomb structure was first proposed by Majda [xiii] with the goal of electrochemical studies of lateral charge transport [xiv].

The second important point is the assembly of the bilayer on the template (figure 1B). The idea is to mimic the invaginated natural membranes of large surface areas found in mitochondria or thylakoids. Thus, the bilayer has to cover the whole oxide surface to form a continuous two-dimensional structure. The self-assembly of the structure is obtained by accumulation of vesicles inside the pores followed by a fusogen treatment (for example with polyethyleneglycol) allowing the formation of the continuous 
bilayer. This scheme was successful for the assembly of pure lipid bilayer on microporous electrodes with pores on average $100 \mathrm{~nm}$ in diameter [x].

However, the first attempts to introduce integral enzyme complexes by this technology onto the supported bilayer were not successful. The simple idea was to fuse proteoliposomes containing the protein complexes. There are two main causes for this failure:

i) Integral enzyme complexes exhibit hydrophilic domains, often protruding from the membrane plane, which apparently interact non-specifically with the solid support. Such strong non-specific interactions with the surface disorganize the proteoliposome structure and hinder the fusion process. This was evaluated on flat surfaces and we have proposed a solution in a parallel study [xv].

ii) The average diameter of the proteoliposomes used was checked by light scattering and found to be somewhat greater (70 to $100 \mathrm{~nm}$ ) than that of phospholipid vesicles made for example by sonication (30 to $50 \mathrm{~nm}$ ). The accumulation of proteoliposomes inside the $100 \mathrm{~nm}$ pores was therefore unsuccessful because of this simple geometrical constraint. The pore diameter has to be increased to facilitate proteoliposome loading.

The main goal of this paper is therefore to increase the pore diameter to about 160 nm. Simultaneously we have optimized a new, more reliable, process for the production of the microporous electrodes so that: i) the yield of each fabrication step is sufficiently high to allow an acceptable overall yield; ii) the device can be produced easily in a standard laboratory.

\section{Experimental}

L- $\alpha$-Phosphatidyl-ethanolamine-dioleoyl (DOPE), synthetic, L- $\alpha$ phosphatidylcholine (eggPC) type XVI-E from egg yolk, diphosphatidylglycerol (cardiolipin), from bovine heart and ubiquinone (coenzyme $\mathrm{Q}_{10}$ ) were purchased from Sigma (St Quentin Fallavier, France). Biotin-amidocaproic acid 3-sulfo-Nhydroxysuccinimideester (NHS-lc-biotin), streptavidin, n-octyl $\beta$-D-glucopyranoside (OG), polyethylene glycol (PEG-8000), average molecular weight: $8000 \mathrm{~g} \mathrm{~mol}^{-1}$ were also from Sigma. 1,2-Distearoyl-sn-glycero-3-phosphoethanolamine-N[biotinyl(polyethylene glycol)2000] (biotinylated DSPE-PEG) was from Avanti polar-lipid. NHS-PEG-333 was from Quanta bioDesign (Powell, OH). Oxalic acid, 
aminopropyl-dimethylethoxysilane (ADMS), octadecyl mercaptan (OM) were from (Aldrich, Strasbourg, France). Aluminum foil, 0.3 mm thick (Al $99.99 \%$ ) was from Merck (Darmstadt, Germany).

\section{Preparation of the microporous electrodes:}

The electrodes were prepared by vapor deposition of about $2 \mu \mathrm{m}$ of gold on thin porous aluminum oxide films (thickness typically $7 \mu \mathrm{m}$ ) produced in the laboratory. Miller and Majda initiated the procedure 20 years ago [xvi] and we have changed or simplified several steps.

Aluminum foil (78x30x0.3 mm) was annealed at $400^{\circ} \mathrm{C}$ for $2 \mathrm{~h}$ and mounted into a plastic holder to avoid anodic corrosion on the back of the foil. A first oxide film was generated by anodic corrosion in oxalic acid $\left(0.04 \mathrm{M}\right.$ at $\left.4^{\circ} \mathrm{C}\right)$ for $5 \mathrm{~min}$ at $100 \mathrm{~V}$. This first film was removed by dissolution in boiling acetic acid at 20\% and anodic corrosion was repeated under the same experimental conditions but for 20 min to produce the final film. The oxide film was separated by chemical oxidation of the aluminum substrate from the back of the foil by introducing a solution of $\mathrm{CuCl}_{2}(0.2$ $\mathrm{M}$ in $20 \% \mathrm{HCl}$ ). Aluminum dissolution was very fast (typically $30 \mathrm{~s}$ ) and the oxide film was immediately collected in a large amount of water with the help of a nylon sieve. The barrier layer was removed and the pores enlarged by dipping the oxide pieces (size $60 \times 20 \mathrm{~mm}$ ) in a solution of $4.25 \%(\mathrm{w} / \mathrm{v})$ phosphoric acid at $30^{\circ} \mathrm{C}$ for $30 \pm$ $1 \mathrm{~min}$. This step is considerably easier and more reliable than the "flotation step" we routinely used in previous papers [xvii]. After extensive rinse in water, the second rinse was in a bath of $0.025 \mathrm{M} \mathrm{NaOH}$ for 1 min immediately followed by extensive rinsing in water and drying at $60^{\circ} \mathrm{C}$. The oxides were transferred into a vacuum deposition apparatus (Edwards model E306A) and positioned at $45^{\circ}$ to the evaporation source. They were successively coated at $0.1 \mathrm{~nm} / \mathrm{s}$ with a ca. $4 \mathrm{~nm}$-thick layer of chromium (used for oxide/gold adhesion) and at $7 \mathrm{~nm} / \mathrm{s}$ with a ca. $2 \mu \mathrm{m}$-thick layer of gold. Finally, the gold-coated oxide films were mounted on the tip of a glass tube to produce a microporous electrode ( $3 \mathrm{~mm}$ in diameter), using conductive silver glue for electrical contact.

Geometrical characterization of the oxide films (thickness, pore density and pore size) was routinely performed by environmental scanning electron microscopy (ESEM, XL 30 from Philips). 
Supported bilayer assemblies on the streptavidin sub-layer:

The solid interfaces of the microporous electrodes were first functionalized by chemical grafting: gold at the pore bottom with an alkylthiolate and aluminum oxide with a silane. These treatments were performed simultaneously by dipping the electrode tip overnight in a acetone/water solution (95/5, v/v) containing $0.2 \mathrm{mM} \mathrm{OM}$ and $60 \mathrm{mM}$ ADMS. After successive rinsing in acetone, methanol and Milli-Q water to remove unbound molecules, the electrodes were stored in phosphate buffer.

The streptavidin sub-layer was self-assembled on the amine layer in two steps. First the microporous electrode was dipped for $45 \mathrm{~min}$ in a mixture of NHS reactants (10 $\mathrm{mM}$ ) in a phosphate buffer $50 \mathrm{mM}$ pH 8:The molar ratio between NHS-PEG-333 and NHS-lc-biotin was $0.1 \mathrm{~mol} \%$. After rinsing, the electrode was dipped for $1 \mathrm{~h}$ in a 5 $\mu \mathrm{g} / \mathrm{mL}$ streptavidin solution in the PBS buffer (phosphate buffer $0.01 \mathrm{M}$ at $\mathrm{pH} 7.4+$ $0.15 \mathrm{M} \mathrm{NaCl}$ ). A detergent rinse with $50 \mathrm{mM}$ OG solution to reduce non-specific binding was followed by extensive rinsing in the phosphate buffer.

For the formation of the supported bilayer, the microporous electrodes were incubated for $1 \mathrm{~h}$ at $30^{\circ} \mathrm{C}$ in a solution of biotinylated vesicles (egg-PC: $45.8 \mathrm{~mol} \%$; DOPE: 34\%; cardiolipin: 18\%; ubiquinone: 2\%; biotinylated DSPE-PEG: 0.2\%) prepared in phosphate buffer as previously described [x]. After rinsing with the buffer, the fusion of the immobilized vesicles was triggered by a PEG-8000 30\% (w/v) solution.

\section{Electrochemical measurements.}

The anaerobic electrochemical cell contained three electrodes: the working microporous electrode, platinum foil auxiliary electrode, and a $\mathrm{KCl}$-saturated aqueous calomel reference electrode $(\mathrm{SCE}=0.234 \mathrm{~V}$ vs. the normal hydrogen electrode at $30^{\circ} \mathrm{C}$ ) to which all potentials are referred. Gentle bubbling of argon or nitrogen reduced the partial pressure of oxygen in the main compartment thermostated at $30^{\circ} \mathrm{C}$ by water circulation.

A Voltalab 32 controlled by a PC computer and a Voltamaster software package (Tacussel, Radiometer Analytical) were used for cyclic voltammetry and chronocoulometry. 


\section{Results}

\section{Aluminum oxide preparation:}

The parameters governing the electrochemical formation of alumina nano-structures have been widely studied (see for example [xii] or [xviii]). The diameter of the individual cells of the hexagonally ordered structure depends on $\mathrm{pH}$, anodization voltage, choice of acid and temperature. After several attempts, we chose anodization at $100 \mathrm{~V}$ in $40 \mathrm{mM}$ oxalic acid at low temperature $\left(4^{\circ} \mathrm{C}\right)$ giving an average cell size of about $220 \mathrm{~nm}$ (figure 2A). We found, in agreement with the literature [xii,xviii], that two successive anodizations (the second one after removing the first oxide layer by dissolution) produced a more ordered pore structure than a simple anodization. The time of the pore-widening treatment in a $4.2 \mathrm{wt} \%$ phosphoric acid solution was optimized by ESEM observations and judged satisfactory for $30 \pm 1 \mathrm{~min}$ at $30^{\circ} \mathrm{C}$ (figure 2). Under these conditions the geometrical parameters of the routinely produced oxide films are the following:

- final macroscopic size about 60x20 mm, thickness: $7 \pm 1 \mu \mathrm{m}$.

- microscopic structure: average pores diameter: $170 \mathrm{~nm}$, thickness of the pore wall: $50 \mathrm{~nm}$, average pore density: $2.410^{9}$ pores $/ \mathrm{cm}^{2}$, pore crossing: less than $5 \%$.

From these parameters and assuming that the pores are essentially cylindrical, the overall surface area of the pores is estimated to be $90 \pm 10 \mathrm{~cm}^{2}$ per $\mathrm{cm}^{2}$ of oxide.

\section{Gold/aluminum oxide adhesion:}

To the best of our knowledge, all the experimental procedures previously published for the deposition of gold on porous aluminum oxides used direct coating without any adhesion layer (either on the commercially available "anopore" membranes from Whatmann [for example:xix] or on laboratory-made oxides [xvi,xx, $\mathrm{x}]$ ). However we have found that the adhesion between the two materials was finally not reliable for long-term use (at least one week) of the composite structure. Any temperature shock, even as little as storage at $4^{\circ} \mathrm{C}$, induced a progressive separation of gold from oxide. An alternative approach, routinely used for glass substrates, is to introduce a thin (a 
few nanometers) transition metal underlayer to enhance the gold adhesion. Two metals were tested for this purpose: aluminum and chromium both at a thickness of about $4 \mathrm{~nm}$. A simple qualitative test using standard adhesive tape was used to examine the efficiency of the underlayer. The gold face of the gold/transition metal/oxide composite was epoxy-glued onto a glass surface. The adhesive tape was firmly placed on the oxide and then removed. In the case of direct gold deposition on oxide, the oxide was completely removed by the tape. In the case of $\mathrm{Al}$ or $\mathrm{Cr}$ underlayers, the oxide was not stripped off during the test, demonstrating better adhesion. Finally, the mechanical adhesion being similar for $\mathrm{Al}$ or $\mathrm{Cr}$, we chose a chromium underlayer as the electrochemical behavior of the electrode was better in this case.

This simple variant increased considerably the life-time of the microporous electrodes, as demonstrated below in the electrochemical studies.

\section{Assembly of the tethered phospholipid bilayer on the microporous template:}

The structure of the microporous electrode allowed electrochemical monitoring of the tethered bilayer formation. As electroactive marker, we used ubiquinone (coenzyme $\mathrm{Q}_{10}$ ) a strictly water-insoluble molecule which was dissolved at low concentration in the hydrophobic leaflet of the phospholipid bilayers. If ubiquinone is able to reach the gold electrode (and thus is electrochemically reduced), the continuity of the bilayer can be attested by a cathodic current demonstrating the long-range diffusion in two dimensions of this molecule. The assembly of the lipid hemilayer at the electrode interface was facilitated by a preliminary treatment of gold with an alkyl thiol (OM, see experimental). Furthermore, this treatment lowered the background currents and increased the signal-to-noise ratio.

The aluminum oxide surface was chemically modified in such a way that biotinylated vesicles (containing 2 mol\% of ubiquinone) be specifically immobilized on a streptavidin sublayer (see experimental). At this stage, schematized in figure $1 \mathrm{~B}$, the vesicles are isolated from each other and ubiquinone molecules are not detected by the electrode. Under the fusogen treatment, the vesicles fuse, the tethered bilayer spreads out and ubiquinone molecules are electrochemically detected.

Figure 3 shows an example of triggered bilayer formation. At the low scan rate used ( $2 \mathrm{mV} / \mathrm{s}$ ), integration of the cathodic peak gives the total amount of ubiquinone dissolved inside the tethered bilayer. The ubiquinone concentration in two dimensions 
can be deduced from this charge: $13.3 \mu \mathrm{C}$; the number of electrons exchanged: 2 per mol and the surface area of the porous template: $90 \times 0.07=6.3 \mathrm{~cm}^{2}$ per electrode. We found 10.9 picomole $/ \mathrm{cm}^{2}$ of oxide surface area (an average of $10.5 \pm 1.5$ picomole $/ \mathrm{cm}^{2}$ for different batches of electrodes), in good agreement with 10 picomol $/ \mathrm{cm}^{2}$, the value calculated from the molar fraction of quinone in the vesicles ( 2 mol\%) and from the mean surface area of a lipid in the bilayer $\left(67 \AA^{2}\right)$. This agreement demonstrates that the whole oxide surface was covered, as expected, by a continuous bilayer connected to the alkylated gold.

The results of several electrochemical controls are summarized in the following:

- At scan rates higher than $5 \mathrm{mV} / \mathrm{s}$ (not shown) the shape of the voltammogram peaks changes and becomes more diffusive (see lateral diffusion coefficient measurement).

- Continuous cycling for one day, for example at $2 \mathrm{mV} / \mathrm{s}$ gives superimposed traces.

- The microporous electrodes loaded with tethered bilayers are stable even after several successive rinses and overnight storage in buffer solutions at $4^{\circ} \mathrm{C}$. The amount of ubiquinone detected is almost constant (loss of less than $20 \%$ in one week).

- The ubiquinone loadings are proportional to the molar content of ubiquinone in the vesicles (tested between 0.5 and $2 \mathrm{~mol} \%$, see also figure 4).

- We tried to load again with vesicles (still containing 2 mol\% of $Q_{10}$ ) the microporous electrodes already loaded with a tethered bilayer. After buffer rinsing and a new fusion process, the charge increases were negligible (less than $0.5 \mu \mathrm{C}$ ). This is further evidence for the complete formation of a continuous and stable supported bilayer.

- On the contrary, the structure was easily destroyed (the quinone peak was immediately lost) by rinsing with a $40 \mathrm{mM}$ OG solution .

Electrochemical measurement of the lateral diffusion coefficient of $Q_{10}$.

Fluorescence recovery experiments (FRAP) on similar supported bilayer on a flat surface have demonstrated that fluorescent-labeled lipids are normally mobile in the structure $[\mathrm{xv}]$. We therefore checked by chronocoulometry that the ubiquinone molecules were also mobile by lateral diffusion inside the hydrophobic bilayer leaflet. We used the technique first described by Majda [xiv] for the calculation of the diffusion coefficient of electroactive species in two dimensions [ix]. Typical results for two ubiquinone loadings are given in figure 4. 
For different batches of electrodes the diffusion coefficient is $3 \pm 110^{-8} \mathrm{~cm}^{2} \mathrm{~s}^{-1}$ at $30^{\circ} \mathrm{C}$, in good agreement with previous measurements on electrodes with the smaller pore size of $100 \mathrm{~nm}$ [ix,x].

\section{Conclusion}

A new and simpler technology for the production of microporous electrodes has been presented. Here, the pore diameter was optimized at $170 \mathrm{~nm}$ but, with the help of an adhesive chromium underlayer, the production of stable microporous electrodes with pores between 20 and $250 \mathrm{~nm}$ could also be envisaged. The loading of a continuous tethered lipid bilayer on this template has been successful, as demonstrated by the electrochemistry in two dimensions of the water-insoluble ubiquinone, which is laterally mobile in the bilayer.

\section{Acknowledgements}

The support of this research by the CNRS through an ACI grant $\mathrm{N}^{\circ}$ A2N062 and by La Région Picardie through a grant from the "Pôle IBFBio" are both gratefully acknowledged. 


\section{References}

[i] E .Sackmann, M.Tanaka, TIBTECH 18 (2000) 58.

[ii] E-K. Sinner, W. Knoll, Curr. Opin. Chem. Biol. 5 (2001) 705.

[iii] B.A. Cornell, V.L.B. Braach-Maksvytis, L.G King, P.D.J. Osman, B. Raguse, L. Wieczorek, R.J. Pace, Nature 387 (1997) 580.

[iv] M.L. Wagner, L.K. Tamm, Biophys. J. 79 (2000) 1400.

[v] L.K. Tamm, H.M. McConnell, Biophys. J. 47 (1985) 105.

[vi] S. Heyse, O.P. Ernst, Z. Dienes, P. Hofmann, H. Vogel, Biochemistry 37 (1998) 507.

[vii] C.A. Keller, K. Glasmastar, V.P. Zhdanov, B. Kasemo, Phys. Rev. Lett. 84 (2000) 5443.

[viii] I. Reviakine, A. Brisson, Langmuir 16 (2000) 1806.

[ix] D. Marchal, W. Boireau, J-M. Laval, J. Moiroux, C. Bourdillon, Biophys. J. 74 (1998) 1937.

[x] V. Proux-Delrouyre, J-M. Laval, C. Bourdillon, J. Am. Chem. Soc. 123 (2001) 9176.

[xi] D. Marchal, J. Pantigny, J-M. Laval, J. Moiroux, C. Bourdillon, Biochemistry 40 (2001) 1248.

[xii] H. Masuda, K. Fukuda, Science 268 (1995) 1466.

[xiii] C.J. Miller, M. Majda, J. Am. Chem. Soc. 107 (1985) 1419.

[xiv] M. Majda In: Kinetics and Catalysis in Microheterogeneous Systems.M. Gratzel and K. Kalyanasundaram, Eds, Marcel Dekker, Inc, New York, (1991) 227.

[xv] C. Elie-Caille, O. Fliniaux, J. Pantigny, J-C. Mazière, C. Bourdillon. Langmuir, (2005) in press.

[xvi] C.J. Miller, M. Majda, J. Electroanal. Chem. 207 (1986) 49.

[xvii] V. Proux-Delrouyre, C. Elie, J-M. Laval, J. Moiroux, C. Bourdillon, Langmuir 18 (2002) 3263.

[xviii ] F. Li, L. Zhang, R.M. Metzger, Chem. Mater. 10 (1998) 2470.

[xix] B. Ballarin, C.J. Brumlick, Del R. Lawson, W. Liang, L.S. Van-Dyke, C.R. Martin, Anal. Chem. 64 (1992) 2647.

[xx] K. Uosaki, K. Okazaki, H, Kita, H. Takahashi, Anal. Chem. 62, (1990) 652. 